\title{
Influence of Low Temperature on the Evolution of Amino Acid Pools Adaptive Modifications inPoikilothermal
} Animals

\author{
Margarita V. Karanova \\ Institute of Cell Biophysics of RAS, Cryopreservation of genetic resources laboratory, Pushchino, Moscow region, Russia, 142290 \\ *Corresponding Author: r_karanova@land.ru
}

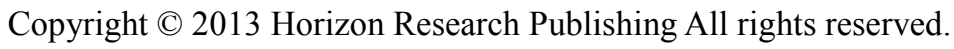

\begin{abstract}
Interpretation of phylogenesis in the light of comparative biochemistry is currently still limited. Adaptive changes in the concentration of the FAA in response to the decrease in temperature are one of the essential features of poikilothermic animals living in areas with large temperature difference. It is purpose of this review to reveal the hierarchy of certain biochemical sign, namely the FAA that underlie of differences in invertebrate and vertebrate poikilotherms and in the process of evolution begin to discover themselves only at low temperatures. The review summarizes literature and author information about evolutionary development of adaptive FAA responses of poikilothermic animals, at different levels of phylogenesis, as a result of the seasonal drop in temperature to negative or zero values. It is concluded that the non-specific accumulation of proteinogenic amino acids, characteristic for many invertebrates, is replaced in the vertebrates animals by the accumulation of new participants in the mechanisms of the low temperatures adaptation, which is a nonproteinogenic sulphoamino acid, taurine, and in the brain it is PEA and phosphoamine acid, PS.
\end{abstract}

Keywords Evolution, Adaptation, Low Temperatures, Poikilothermal Animals, Brain, Phosphoethanolamine, Phosphoserine, Taurine.

\section{Introduction}

It is presumed that global climate change is one of the main driving forces behind the evolution of living organisms [1].Mutations of genes seem to occur more frequently during periods of cooling, giving a powerful impetus to the evolution of organisms and resulting intensive formation of new types $[2,3]$. Traces of a progressive evolutionary change, their stages and "witty" finds can be seen when studying the effect of low temperatures on the biochemical mechanisms in different types of ectothermic animals. The expression of many genes that encode proteins involved in signal transductions and chaperones may be changed when exposed to cold shock or cold acclimation [4-6]. The synthesis of cold-induced proteins and modification of existing proteins, conversion of lipid composition of cell membranes, activation of isoenzymes, change of ion, oxygen and metabolite transport are required for adaptation of poikilothermic animals to rapid decreases in environmental temperatures $[7,8]$. In addition, there are the syntheses or accumulation of substances that perform the cryoprotective function (alcohols, sugar, antifreeze proteins, ice-nucleating agent) [9-12]. The FAA and PEA, that is an ethanolamine derivative, also contribute their mite in biochemical strategy of low-temperature adaptation.

\section{Seasonal Changes of the FAA Pool in the Invertebrates}

The content of certain FAA is notably increased in the blood, hemolymph and in bodies of poikilothermic animals, both invertebrates and vertebrates when exposed to low temperatures as a result of the change of seasons or the sudden cold stress. The FAA which perform functions of membrane protectant, osmolytes or antioxidants [13-15], differ depending on the stage of the macroevolution or habitats [9-11]. Accumulation of the FAA in invertebrates (except for intertidal shellfish $[16,17]$ ) is the less than in vertebrates and not accumulated FAAare specific for low-temperature adaptation [18-24]. In addition, a common classifies sign of "protective" the FAA for most invertebrate is that all they are proteinogenic ("protein-building") amino acids, that is, they combine into peptide chains to form the building blocks of proteins. Most of the accumulated amino acids are glucoplastic (e.g., alanine, glutamate, glycine, proline, serine, valine, histidine) [18-24]. Many of them are active participants in the metabolism.

Taking into account the huge variety of the animal world, you should not expect that all types and classes of 
poikilothermic animals must be examined in the context of the response FAA to cold temperatures impact, but even scattered evidence of comparative biochemistry can give an idea about the typical features of pool FAA adaptive modifications of the poikilotherms. Now, thanks to sufficient works on changes of amino acid pools of cryotolerant and cryoresistant invertebrates when exposed to cold, we know about representative features of their adaptive FAA responses [16-24]. Thanks to the work performed on the intertidal molluscs and mussels, surviving temperatures down to- $10^{\circ} /-15^{\circ} \mathrm{c}$, it is known about the specific FAA pattern of these species of marine invertebrates [16, 17].For example, the pool of taurine in leg muscle of the Littorinalittorea is $77 \%$ of the total FAA pool - both at freezing to $-4^{\circ} \mathrm{C}$ and in control at $5^{\circ} \mathrm{C}$ [17]. In gill, mantle, and muscle of the marine mussel Geukensiademissus, taurine together with glycine amount to $80-85 \%$ of the total pool at the 2 or $12 \mathrm{~h}$ freezing to $-6^{\circ} \mathrm{C}$ [16].

Ecological factors such as average annual temperature, water salinity significantly affect the biochemical features even related of poikilothermic animals. It is not surprising that the biochemical properties of adaptation in freshwater molluscs, wintering at a temperature of about $0^{\circ} \mathrm{C}$, different from the above-mentioned properties for intertidal molluscs $[22,23]$. Unfortunately, the study of freshwater hydrobionts in this direction is virtually non-existent, and the author canmention only data on fresh water molluscLymnaea Stagnalis [22, 23]. Accordingto our data, the great pond snail L. stagnalis, hibernating in winter deep in pond clay until spring, contains taurine in summer and before winter hibernation only in trace quantities (Table 1, Fig. 1) [23]. At a decrease of the temperature to $0^{\circ} \mathrm{C}$ at the autumn period, concentration of free alanine in body fluids of L. stagnal is increased in 2,7 times (Table 1). Pool of alanine as a percentage of the total FAA pool, which grows also, increased in 1,4 times and amounts to $25.8 \%$ (Fig. 1). An increase of histidine, glutamate, glycine, and serine concentrations was less pronounced.

Table 1. Amino acid pool changes in tissue fluids of mollusk L. stagnalis before the winter hibernation $\left(\mu \mathrm{mol} / 100 \mathrm{ml}^{-1}\right)[23]$.

\begin{tabular}{|ccc|}
\hline Aminoacid & June & October \\
\hline Taurine? & $\operatorname{tr}$ & $\operatorname{tr}$ \\
Threonine & $25,2 \pm 1,7$ & $20,4 \pm 0,4$ \\
Serine & $21,9 \pm 1,9$ & $37,0 \pm 2,3$ \\
Glutamic & $55,1 \pm 2,1$ & $69,3 \pm 4,4$ \\
Proline & $24,0 \pm 7,7$ & - \\
Glycine & $38,5 \pm 2,1$ & $59,5 \pm 2,9$ \\
Alanine & $47,1 \pm 2,1$ & $128,4 \pm 7,5$ \\
Cysteine/Cystine & - & $29,7 \pm 15,3$ \\
Valine & $11,5 \pm 1,2$ & $22,6 \pm 0,9$ \\
Methionine & $3,0 \pm 0,8$ & $7,0 \pm 1,3$ \\
Isoleuzine & $10,5 \pm 1,2$ & $16,2 \pm 0,7$ \\
Leuzine & $10,2 \pm 1,4$ & $20,5 \pm 0,9$ \\
Tyrosine & $\operatorname{tr}$ & $10,6 \pm 1,4$ \\
Phenylalanine & $\operatorname{tr}$ & $14,7 \pm 1,5$ \\
Histidine & $8,1 \pm 1,2$ & $27,1 \pm 1,7$ \\
Lysine & - & $20,5 \pm 1,2$ \\
\hline Total & $264,4 \pm 21,2$ & $497,0 \pm 42,1$ \\
\hline
\end{tabular}

Values are means $\pm \sigma(n=3)$; $\operatorname{tr}$ - substance was discovered in trace quantities. The animals were captured in late October.
Increasing the concentration of free alanine during adaptation of L. stagnalis, correlated with increasing levels of serine (Table 1), is typical as well for insects, as for example the southwestern corn borer and the European corn borer in relation to their diapause [9,18].Some types of insects during the period of seasonal adaptations increase the level of free alanine and proline [9]. Increased alanine, histidine, glycine and lysine pools, which is typical of freshwater mollusk L. stagnalis, happens in the hemolymph of oak silkworm Antheraea pernyi along with increased proline, arginine and lysine [19].Increase of alanine, lysine, glycine and phenylalanine is also shown for larvae of the wax moth Galleria mellonellaL.[20].Alanine, glutamate, valine and lysine pools among some species of beetles are also increased as a result of adaptation to the low temperature [21].

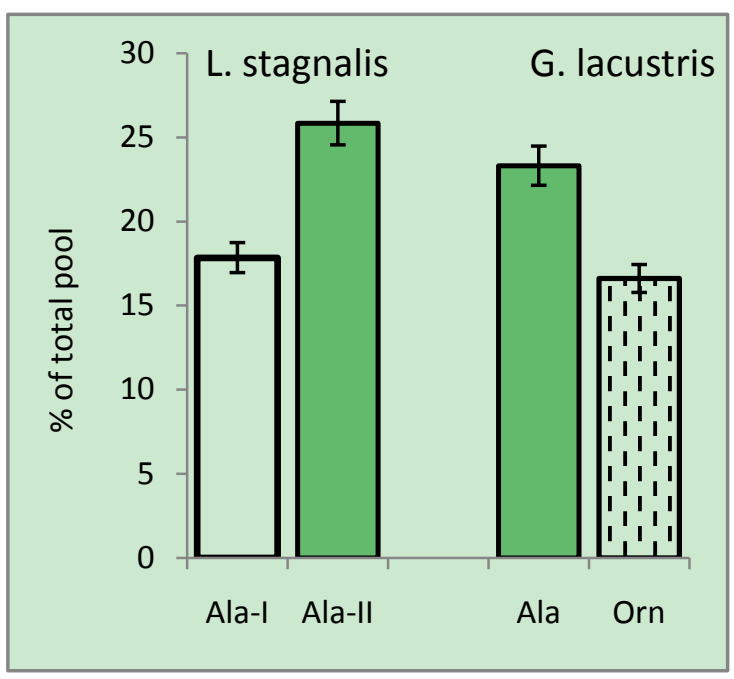

Figure 1. The most abundant amino acid pools of mollusk L. stagnalis and amphipod G. lacustris before the winter hibernation. Ala-I and Ala-II alanine pools of L. stagnalis in June (control) and in October, respectively; Ala, Orn - alanine and ornithine pools of G. lacustris in September.

On the basis of such fragmentary data, it would be reasonable to suppose that in the world of invertebratesat some stages of phylogenesisthere is no specificity of adaptive responses of the FAA at low temperatures, and in the process of compensatory increasing of total FAA pool involved many proteinogenic amino acids, which are mostly the same for different types of organisms.

The appearance at any stage of phylogenesis non-proteinogenic amino acids, accumulated during the period of seasonal temperatures fall, their specific reaction to cold are a marker of the transition to a higher level of evolution. For example, our data show that ornithine pool in hemolymph of freshwater higher crustaceans Gammaruslacustric, living in an area with large difference of summer and winter temperatures, in autumn is $16.5 \%$ of the total FAA pool, taking second after alanine, which is $23.3 \%$ (table 2, Fig 1) [24]. However, this non-proteinogenic amino acid is not detected in the freshwater amphipod Gammarus pseudolimnaeus, living in a warmer climate zone [25]. 
Table 2. Amino acid pools of amphipod G. lacustrisin run-up to the winter hibernation [24].

\begin{tabular}{|ccc|}
\hline Aminoacid & $\begin{array}{c}\mu \mathrm{mol} / \mathrm{ml} \text { of } \\
\text { homogenate }\end{array}$ & $\begin{array}{c}\% \text { of } \\
\text { total } \\
\text { pool }\end{array}$ \\
\hline Taurine & $2,08 \pm 0,15$ & 2,2 \\
Aspartic & $1,12 \pm 0,12$ & 1,2 \\
Threonine & $3,35 \pm 0,68$ & 3,5 \\
Serine & $5,28 \pm 0,86$ & 5,4 \\
Glutamic & $5,76 \pm 0,59$ & 5,9 \\
Proline & $4,5 \pm 0,31$ & 4,6 \\
Glycine & $3,9 \pm 0,42$ & 4,0 \\
Alanine & $22,6 \pm 1,39$ & 23,3 \\
Valine & $5,03 \pm 0,23$ & 5,2 \\
Methionine & $2,04 \pm 0,22$ & 2,1 \\
Isoleuzine & $3,82 \pm 0,21$ & 3,9 \\
Leuzine & $6,32 \pm 0,44$ & 6,5 \\
& $2,01 \pm 0,11$ & 2,1 \\
Tyrosine & $2,65 \pm 0,20$ & 2,7 \\
Phenylalanine Histidine & $1,94 \pm 0,23$ & 2,0 \\
Lysine & $8,39 \pm 0,55$ & 8,7 \\
Ornithine & $17,0 \pm 1,4$ & 17,6 \\
Arginine & tr & tr \\
\hline Total & $96,8 \pm 8,2$ & 100 \\
\hline
\end{tabular}

Values are means $\pm \sigma(n=3)$. The collection of animals was conducted in mid-September.

\section{The Upriseof Nonproteinogenic Amino Acidin the Vertebrates Animals at Low Temperatures}

The most impressive data are obtained for non-proteinogenic sulphoamino acidtaurine when studying the effect of low temperatures on the adaptation of fish and reptiles [26-32]. The phenomenon of adaptive accumulation of taurine (2-amino-ethanesulfonic acid) is found first in our works in examining the impact of seasonal temperature drops or cold shock effect on the pattern of FAA in the eurythermal freshwater fish P. glehni [26-27].

In winter, before beginning hibernation, the contents of taurine in the muscles increases over the summer period to 4,3 times, making up 52,6\% of the total FAA pool (table 3, Fig 2) [26]. The level of taurine in the blood rises in December to 7,7 times in comparison with July and is $45 \%$ of the total pool (table 4, Fig 2) [26].In contrast to the proteinogenic amino acid that alter their pools during the three-month hibernation of P. glehni in ice, level of taurine during this period virtually unchanged, but in the spring, after the release of the winter torpor, turns sharply, accounting for $11,9 \%$ of the total FAA pool [26]. This fact indicates that metabolism is carried out even in a state of torpor at zero temperature and proteinogenic FAA are involved in it. Taurine in the circumstances, is probably associated not with metabolism, and serves as an antioxidant, membrane stabilizator, cellular protectant. Data on accumulation of taurine on earlier, than teleosts, stages of phylogenesis, lacking in the literature, however the exceptions are the above-mentioned intertidal clams and mussels with taurine at negative temperatures is very high $[16,17]$. High levels of taurine in the invertebrate can result in misleading in determining phylogenetic relationships, because this fact is probably an example of biochemical convergence. Taurine in hemolymph of freshwater molluscsL. stagnalisis found at any time of the year only in trace amounts, and in insects taurine is the minimum, and inamphipods G. lacustricone is $2 \%$ of the total FAA pool in the fall [22-24].

Table 3. Influence of seasonal temperature changes on amino acids pools in the blood plasma of freshwater fish P.glehni before beginning hibernation $(\mu \mathrm{mol} / \mathrm{ml})[26]$.

\begin{tabular}{|ccc|}
\hline Amino acid & July & December \\
\hline PS & - & - \\
Taurine & $0,24 \pm 0,03$ & $1,85 \pm 0,10$ \\
PEA & - & - \\
Aspartic & $0,08 \pm 0,01$ & $0,06 \pm 0,01$ \\
Threonine & $0,25 \pm 0,06$ & $0,17 \pm 0,01$ \\
Serine & $0,36 \pm 0,03$ & $0,28 \pm 0,01$ \\
Glutamic & $0,34 \pm 0,04$ & $0,27 \pm 0,02$ \\
Proline & $0,33 \pm 0,04$ & - \\
Glycine & $0,43 \pm 0,04$ & $0,35 \pm 0,01$ \\
Alanine & $0,50 \pm 0,02$ & $0,52 \pm 0,02$ \\
Valine & $0,21 \pm 0,01$ & $0,09 \pm 0,01$ \\
Cystathionine & - & $0,14 \pm 0,03$ \\
Methionine & $0,06 \pm 0,01$ & $0,14 \pm 0,01$ \\
Isoleuzine & $0,15 \pm 0,01$ & - \\
Leuzine & $0,25 \pm 0,01$ & - \\
GABA & - & $0,36 \pm 0,04$ \\
Tyrosine & $0,17 \pm 0,01$ & - \\
Phenylalanine & $0,39 \pm 0,04$ & - \\
Histidine & $0,24 \pm 0,53$ & $0,07 \pm 0,01$ \\
Lysine & $0,19 \pm 0,01$ & $0,10 \pm 0,01$ \\
Arginine & $0,20 \pm 0,01$ & - \\
\hline Total & $4,40 \pm 0,08$ & $4,11 \pm 0,16$ \\
\hline
\end{tabular}

Values are means $\pm \sigma(n=3) ; P<0.05$.Catching the animals on December 26 .

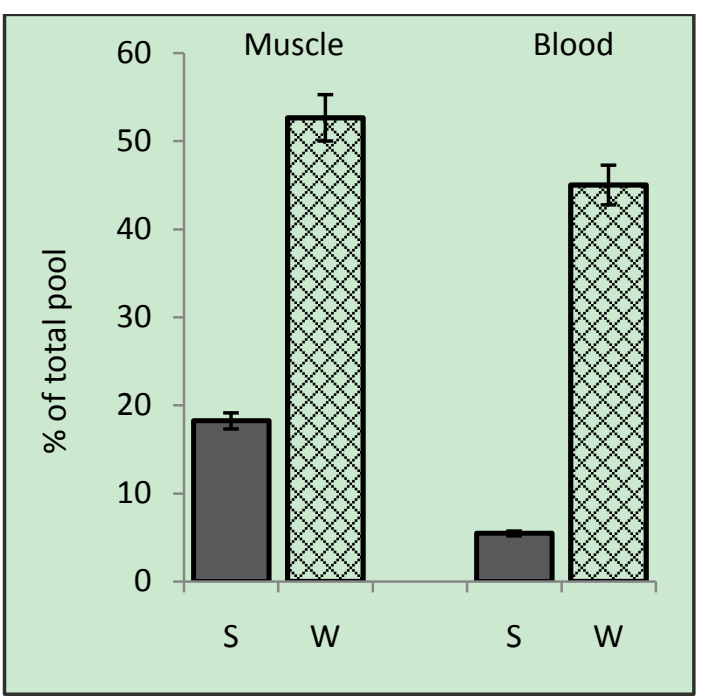

Figure 2. Increase the pool of taurine in muscles and in blood plasma of eurythermal freshwater fish P.glehnibefore beginning hibernation. $\mathrm{S}-$ summer (July), W - winter (December). 
Having successfully carried out its tasks with a low-temperature adaptation of teleosts,taurinemoves to a higher level of evolution, including reptiles and mammals [29-34]. Data on low temperature modifications the FAA pools for amphibians could not be found in the literature, however, the work carried out on reptilian, reported high content of taurine in plasma and organs of various species of snakes and turtles at moderate temperatures and about a significant increase in the pool of taurineat negative temperatures [29, 30]. The total FAA pool in turtle blood C. pictamarginata after a three-day exposition at temperatures from -6 to $-8^{\circ} \mathrm{C}$ increases at 2,25times, and $52 \%$ of increase is due to the taurine [29]. Increased more than 2 times of taurine concentration in freezing up to $-2,5^{\circ}$ Coccurs in the muscles of the garter snake $T$. sirtalisparietalis [30]. Elevation of taurine level in 1,5-3 times is observed in the blood, brain and liver of urchins during winter hibernation and artificial hypothermia in summer [34]. And now, taurine is a ubiquitous amino acids in the human bodyof a wide spectrum of effects. These include stabilization of plasma membrane, modulation of intracellular calcium homeostasis, prevention of cell apoptosis, osmoregulation, reactive-radical scavenging, oxidative stress, neuromodulation and neurotransmission, protein phosphorylation modulation etc. [35-38].

Table 4. Seasonal changes of FAApool in the muscleof freshwater fish $P$. glehni $(\mu \mathrm{mol} / \mathrm{g}$ wet weight $)[26]$.

\begin{tabular}{|lcc|}
\hline Aminoacid & July & December \\
\hline PS & - & - \\
Taurine & $3,26 \pm 0,40$ & $14,06 \pm 0,99^{*}$ \\
PEA & - & - \\
Aspartic & $0,07 \pm 0,01$ & - \\
Threonine & $1,59 \pm 0,13$ & $0,96 \pm 0,07^{* *}$ \\
Serine & $0,9 \pm 0,1$ & $0,46 \pm 0,04^{* *}$ \\
Glutamic & $0,97 \pm 0,08$ & $1,50 \pm 0,11^{* *}$ \\
Proline & $1,24 \pm 0,12$ & - \\
Glycine & $2,0 \pm 0,15$ & $1,47 \pm 0,06^{* *}$ \\
Alanine & $1,5 \pm 0,13$ & $2,92 \pm 0,33^{* *}$ \\
Valine & $0,53 \pm 0,05$ & $0,29 \pm 0,03^{* *}$ \\
Cystathionine & - & $0,98 \pm 0,09$ \\
Methionine & $0,04 \pm 0,01$ & $0,18 \pm 0,01^{*}$ \\
Isoleuzine & $0,15 \pm 0,01$ & $\operatorname{tr}$ \\
Leuzine & $0,31 \pm 0,02$ & $\operatorname{tr}$ \\
GABA & - & $2,40 \pm 0,13$ \\
Tyrosine & $1,08 \pm 0,09$ & $0,94 \pm 0,11$ \\
Phenylalanine & $1,14 \pm 0,06$ & $0,19 \pm 0,01^{*}$ \\
Histidine & $2,06 \pm 0,12$ & $0,43 \pm 0,04^{*}$ \\
Lysine & $0,87 \pm 0,09$ & $0,38 \pm 0,04^{* *}$ \\
Arginine & $0,49 \pm 0,04$ & - \\
\hline Total & $17,88 \pm 1,02$ & $26,71 \pm 0,90^{* *}$ \\
\hline
\end{tabular}

Values are means $\pm \sigma(\mathrm{n}=3) ;{ }^{*} \mathrm{P}<0,001, * *-\mathrm{P}<0.05$.Catching the animals on December 26.

\section{PEA and Taurine in the Brain of Vertebrates at Low Temperatures}

Unexpected facts were found by us when examining low-temperature responses of the FAA in the brain of eurythermal fresh water fish $P$. glehni[27, 28].It turned out that seasonal decrease in temperature, as well as the effect of cold shock, stimulates the emergence in the fish brain of two new members, PEA and PS, which are linked to the structure of membrane phospholipids [39-41];PEA is a derivative of ethanolamine, and PS is nonproteinogenic amino acid. The appearance of PEA and PS is specific to the brain of fish because in plasma and in the muscle these amino acids are not detected either in summer or in winter [27]. PEA in the brain of $P$. glehni accumulates in much greater numbers than PS. Pool of PEA, consisting in the middle of summer only $0,3 \%$ of the total FAA pool, at the beginning of winter rising to $33,6 \%$ (table 5, Fig 3). PS, which not found in the summer in a free form, at the beginning of winter is $3,75 \%$ of the total pool (table 5) [28]. It is also interesting that accumulation of the PEA has a negative correlation with the content of taurine $[27,28]$. In contrast to the usual increase of taurine level in the blood and organs at low temperatures, in the brain of fishtaurine is declining against the background of increasing levels of PEA and PS(table 5, Fig 3).

Table 5. Seasonal changes of FAA and PEA pool in the brain of freshwater fish P. glehni (nmoles/g wet weight) [28].

\begin{tabular}{|ccc|}
\hline Aminoacid & June & December \\
\hline PS & 0 & $410 \pm 43$ \\
Taurine & $3897 \pm 166$ & $905 \pm 66^{*}$ \\
PEA & $39 \pm 15$ & $3663 \pm 137^{*}$ \\
Aspartic & $82 \pm 7$ & 0 \\
Threonine & 0 & $14 \pm 4$ \\
Serine & 0 & $614 \pm 37^{*}$ \\
Glutamic & $2079 \pm 140$ & $344 \pm 22^{*}$ \\
Glycine & $947 \pm 53$ & $669 \pm 40^{*}$ \\
Alanine & $896 \pm 39$ & $717 \pm 66^{* *}$ \\
Valine & $203 \pm 17$ & $76 \pm 13^{*}$ \\
Isoleuzine & $25 \pm 3,5$ & 0 \\
Leuzine & $33 \pm 8$ & 0 \\
GABA & $1105 \pm 84$ & $1137 \pm 70$ \\
Tyrosine & $77 \pm 9$ & 0 \\
Histidine & $3290 \pm 283$ & $2167 \pm 94^{*}$ \\
Lysine & $602 \pm 51$ & $214 \pm 20^{*}$ \\
\hline Total & $13275 \pm 481$ & $10931 \pm 198^{* *}$ \\
\hline
\end{tabular}

alues are means \pm s.e. $\mathrm{m}(\mathrm{n}=4) ; *_{-} \mathrm{P} \leq 0,001 ; * *-\mathrm{P} \leq 0,05$.

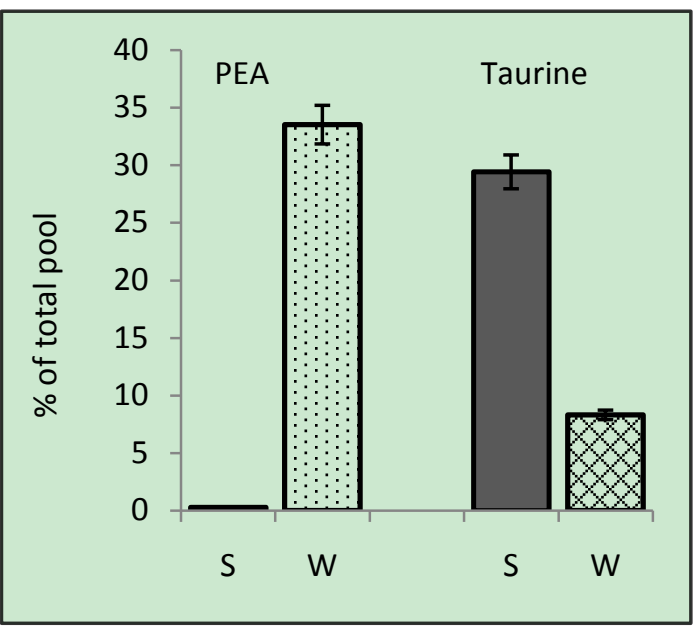

Figure 3. Influence of seasonal temperature changes on PEA and taurine pools in the brain of eurythermal freshwater fish P.glehni. S - summer(July), $\mathrm{W}$ - winter (December). 
The absence of serine in the summer,but high level in winter and substantial increase at impact of cold shock are also characteristic fact of low temperature adaptation in the brain of $P$. glehni $[27,28]$.Metabolism of serine is associated with PEA via ethanolamine (serine $\rightarrow$ ethanolamine $\rightarrow$ PEA). This hydroxyamino acid is one of the key figures of the phospholipid metabolism in brain, turning into phosphatidylserine by the reaction with phosphatidylcholine or PtdE, as well as participating in the synthesis of sphingolipid molecules [39]. Increasing the concentration of PEAand serine are likely reflects changes in the phospholipid component of cell membranes at low temperatures. It is appropriate to add that negative correlation of serine and taurinepools in the brain $P$. glehni(table 5) was specifiedalso in the experiments on brain slices of chicken, where it was shown that perfusion of L-serine reduced the concentration of taurine [42].

Despite wide expansion of PtdE in the animal world, literary data on the presence in the brain poikilotherms of free PEA are missing, although there are sometimes messages about its detection in whole body of invertebrates $[21,43]$. Discrete, dependent on temperature, the presence of PEA and PS in the brain of teleosts presumes the start of such change inevolution of the animal world, in which a special role will be given to thissubstances, which related, probably,to adaptive changes of membrane sphingomyelin or phospholipid metabolism [44-46]. For example, accumulation of PEA, which is an intermediate substrate in the synthesis of PtdE and phosphatidylcholine[40, 41, 45, 46], could be explained by removal of PEA from PtdE by phospholipase $\mathrm{C}$.

Indeed, an eukaryotic cells have phospholipase $\mathrm{C}$ that cleave link between glycerine and the phosphate group in most types of phospholipids, however phospholipase $\mathrm{C}$ of an eukaryotesdoes not disconnect this link in PtdE[47, 48]. The enzyme, cleaving this link precisely in PtdE, was found only in pathogenic bacteria Clostridium perfringens, synthesizing «aggressive enzymes» such as proteinase, lecithinase, collagenase, hyaluronidase and $\alpha$-toxin, which is a phospholipase C [49].In eukaryotic cells such enzyme is still not detected for PtdE, so the reliability of the first assumptions is unlikely. It can be presumed that the accumulation of the PEA is due to a breach of PtdE synthesis at the stage of PEA and CTP interaction with the participation of CTP: phosphoethanolamine cytidylyltransferase. The content of PtdE in the membranes of the brain in this case should be decreased, and the PEA should be increased. However, according to Chang and Roots [50, 51], amounts of PtdE in microsomes and inner mitochondrial membranes from brain of goldfish Carassiusauratus increases significantly at low temperatures $\left(5^{\circ} \mathrm{C}\right)$. The content of PtdE increases in the winter not only in the brain $(41 \%)$, but also in edible flesh of rainbow trout and perhaps in other organs[52].

Mention should be made of other interesting data. So, it is shown that the increase PtdE synthesis in isolated rat hepatocytes was accompanied by a considerable increase in the pool size of PEA, whereas the amount of cytidine diphosphate ethanolamine remained constant [53, 54]. Therefore, it can be assumed that the expression of a gene occurs in the brain of eurythermal fishes at low temperatures, inducing the synthesis of isoenzyme of ethanolamine phosphokinase, andATP phosphorylates ethanolamine (forming PEA) in the presence of this is oenzyme with greater speed than at normal temperatures. It is possible PEA in an excessive concentration is the activator of the PtdE synthesis at low temperatures.

Accumulation of free PEA in brain of teleosts when exposed to low temperatures presumes its specific role in evolution. It is unknownabout existence of PEA in the brain jawless and cartilaginous fishes standing at the lower stages of phylogenesis. High level PEA in the brain of mammals [55] and its possible start in the brain of fish suggest that PEAgradually increases its presence in the brain in the process of evolution.

\section{The Algorithm of Evolution}

Further, taking into account the algorithm of evolution, it can be assumed that PEA and PS are absent in ganglia of invertebrate even at low temperatures. The results of our new work performed in autumn on the brain of previously mentioned the freshwater mollusk $L$. stagnalis, confirmed this assumption, but they added again the fact of participation in adaptation to cold the other nonproteinogenic amino acid, namely $ß$-alanine (unpublished data). It can be presumed that discussed PEA and PSshould be kept (and possibly even the enhance) its presence in a brain of superior vertebrates (amphibians, reptiles, birds). This question, in the absence of relevant studies, is still open. It is known that PEA affect the synthesis of acetylcholine in cholinergic neurons [56], initiates apoptosis [57], affects the activity of the $\mathrm{Ca}^{2+}$-dependent mammalian channels [58]. The level of PEA and PS are changed in Alzheimer's disease and Huntington's disease [59-61].

\section{Conclusion}

Striking features of biochemical evolution are suddenly detected when studying the effect of low temperatures upon biochemical adaptation of different classes of poikilothermic animals. Synthesis and accumulation of nonproteinogenic FAA(taurine, PS) and also PEA, which is specific to low temperature, carried out in extreme survival situations only starting from a certain stage of phylogenesis. PEA and PS is a little inherent or absolutely not typical in poikilotherms in normal temperature conditions, in summer, but are becoming gradually norm in the course of evolution the even for the homeothermic animals. The aforenamedsubstancesreflect progressive complication of biochemical organization of animals and indicates that low temperatures caused the revolutionary changes in the central nervous system 
poikilotherms. This review is an attempt to identify one of the branches of the hierarchy, which was a gap in comparative biochemistry.

\section{REFERENCES}

[1] S. Chown, A. Hoffmann, T. Kristensen, M. Angilletta, N. Stenseth, C. Pertoldi. Adapting to climate change: a perspective from evolutionary physiology, Climate Research, Vol.43, 3-15, 2010.

[2] P. Fields. Protein function at thermal extremes: balancing stability and flexibility, Comparative Biochemistry and Physiology - Part A, Vol.129, 417-431, 2001.

[3] P. Ruoff, M.Zakhartsev, H.Westerhoff. Temperature compensation through systems biology, Federation of European Biochemical Societies Journal, Vol.274, 940-950, 2007.

[4] Z. Ju, R. Durham, Z. Liu. Differential gene expression in the brain of channel catfish (Ictaluruspunctatus) in response to cold acclimation, Molecular Genetics and Genomics, Vol. 268, 87-95, 2002.

[5] S. Phadtare, J. Alsina, M. Inouye. Cold-shock response and cold-shock proteins, Current Opinion in Microbiology, Vol.2, No.175-180, 1999.

[6] K. Yamanaka, L. Fang, M. Inouye. The CspA family in Escherichia coli: multiple gene duplication for stress adaptation, Molecular Microbiology, Vol.27, No.2, 247-255, 1998.

[7] J. Hazel, C. Prosser. Molecular mechanisms of temperature compensation in poikilotherms, Physiological Reviews, Vol.54, 620-677, 1974.

[8] P. Hochachka, G. Somero. Biochemical Adaptation. Mechanism and Process in Physiological Evolution, Oxford: Oxford University Press. New York, USA, 2002.

[9] Storey K.B. Metabolism and bound water in overwintering insects // Cryobiol. 1983. V. 20. P.365-379.

[10] K. Storey, J. Storey.Putting life on 'pause' - molecular regulation of hypometabolism, Journal of Experimental Biology, Vol.210, No.10, 1700-1714, 2007.

[11] K. Storey, J. Storey. "Hibernation: Poikilotherms". In: Encyclopedia of Life Science, Ltd: Chichester, 2011.

[12] K. Storey, J. Storey. Insect cold hardiness: recent advances in metabolic, gene and protein adaptation, Canadian Journal of Zoology, Vol.90, No.9, 456-475, 2012.

[13] B. Schobert, H. Tschesche. Unusual solution properties of proline and its interaction with proteins, Biochimica et BiophysicaActa, Vol.541, 270-277, 1978.

[14] L. Tyankova. The effect of amino acids on thylakoid membranes during freezing as influenced by side chain and position on the amino group, BiochimicaetBiophysicaActa, Vol.274, 75-82, 1972.

[15] T. Anchordoguy, J. Carpenter, S. Loomis, J. Crowe.Mechanisms of Interaction of Amino-Acids with
Phospholipid-Bilayers during Freezing, BiochimicaetBiophysicaActa, Vol.946, No.2, 299-306, 1988.

[16] K. Storey, T. Churchill. Metabolic responses to anoxia and freezing by the freeze-tolerant marine mussel Geukensiademissus, Journal of Experimental Marine Biology and Ecology, Vol.188, No.1, 99-114, 1995.

[17] T. Churchill, K. Storey. Metabolic responses to freezing and anoxia by the periwinkle Littorinalittorea, Journal of Thermal Biology, Vol.21, No.1, 57-63, 1996.

[18] T. Morgan, G. Chippendale. Free amino acids of the haemolymph of the southwestern corn borer and the European corn borer in relation to their diapause, Journal of Insect Physiology, Vol.29, 735-740, 1983.

[19] A. Mansingh. Changes in the free amino acids of the haemolymph of Antheraeapernyi during induction and termination of diapause, Journal of Insect Physiology, Vol.13, 1645-1655, 1967.

[20] R. Hanzal, A. Jegorov. Changes in free amino acid composition in haemolymph of larvae of the wax moth, Galleria mellonella L. during cold acclimation, Comparative Biochemistry and Physiology, Vol.100A, 957-962, 1991.

[21] P. Fields, F. Fleurat-Lessard, L. Lavenseau, G. Febvay, L. Peypelut, G. Bonnot. The effect of cold acclimation and deacclimation on cold tolerance, trehalose and free amino acid levels in Sitophilusgranarius and Cryptolestesferrugineus (Coleoptera), Journal of Insect Physiology, Vol.44, 955-965, 1998.

[22] M. Karanova. Variation in the content of free amino acids in body fluids of freshwater mollusk Lymnaeastagnalis during seasonal adaptation to low positive temperatures, Biology Bulletin, Vol.33, No.6, 587-591, 2006.

[23] M. Karanova, E. Gakhova. Biochemical strategy of survival of the freshwater molluscsLymnaeastagnalis at near-zero temperatures, Journal of Evolutionary Biochemistry and Physiology, Vol.43, No.3, 310-317, 2007.

[24] M. Karanova, A. Andreev. Free Amino Acids and Reducing Sugars in the Freshwater Shrimp Gammaruslacustris (Crustacea, Amphipoda) at the Initial Stage of Preparation to Winter Season, Journal of Evolutionary Biochemistry and Physiology, Vol.46, No.4, 279-283, 2010.

[25] R. Graney, J. Giesy. Seasonal Changes in the Free Amino-Acid Pool of The Fresh-Water Amphipod Gammarus-PseudolimnaeusBousfield (Crustacea, Amphipoda), Comparative Biochemistry and Physiology, Vol.85A, No.3, 535-543, 1986.

[26] M. Karanova. Free Amino Acid Composition in Blood and Muscle of the Gobi Perccottusglehniat the Period of Preparation and Completion of Hibernation, Journal of Evolutionary Biochemistry and Physiology, Vol.45, No.1, 67-77, 2009.

[27] M. Karanova. The Effect of Cold Shock on the Free Amino Acid Pool of PondfishPerccottusglehni(Eleotridae, Perciformes), Biology Bulletin, Vol.38, No.2, 116-124, 2011.

[28] M. Karanova. Phosphoethanolamine in the brain of the eurythermal pond fish Perccottusglehni (Eleotridae, Perciformes, Dyb. 1877) as a phenomenon depending on temperature factor, Journal of Evolutionary Biochemistry 
and Physiology, Vol.49, No.3, 2013.

[29] K. Storey, J. Storey, S. Brooks, T. Churchill, R. Brooks.Hatchling turtles survive freezing during winter hibernation, Proceedings of the National Academy of Sciences USA, Vol.85, 8350-8354, 1988.

[30] T. Churchill, K. Storey. Freezing survival of the garter snake Thamnophissirtalisparietalis, Canadian Journal of Zoology.Vol.70, 99-105, 1992.

[31] T. Churchill, K. Storey. Natural freezing survival by painted turtles Chrysemyspictamarginata and C. pictabellii, American Journal of Physiology, Vol.262, No.3, 530-537, 1992.

[32] T. Churchill, K. Storey. Responses to freezing exposure of hatchling turtles Trachemysscriptaelegans: factors influencing the development of freeze tolerance by reptiles, The Journal of Experimental Biology, Vol.167, 221-233, 1992.

[33] S. Benyajati, W. Dantzler. Plasma levels and renal handling of endogenous amino acids in snakes: a comparative study, The Journal of Experimental Zoology, Vol.238, No.1, 17-28, 1986.

[34] K. Al-Badry, T. Hoda. Hibernation hypothermia and metabolism in hedgehogs - changes in free amino acids and related compounds, Comparative Biochemistry and Physiology, Vol.72A, No.3, 541-547, 1982.

[35] R. Huxtable. Expanding the circle 1975-1999: sulfur biochemistry and insights on the biological functions of taurine, Advances in Experimental Medicine and Biology, Vol.483, 1-25, 2000.

[36] M. Bidri, P. Choay. Taurine: a particular aminoacid with multiple functions, AnnalesPharmaceutiquesFrançaises, Vol.61, 385-391, 2003.

[37] S. Schaffer, J. Azuma, K. Takahashi, M. Mozaffari. Why is taurinecytoprotective? Advances in Experimental Medicine and Biology, Vol.526, 307-321, 2003.

[38] C. Buddhala, H. Prentice, J.-Y.Wu.Modes of Action of Taurine and Granulocyte Colony-stimulating Factor in Neuroprotection, The Journal of Experimental and Clinical Medicine, Vol.4, No.1, 1-7, 2012.

[39] J. Vance. Phosphatidylserine and Phosphatidylethanolaminein Mammalian Cells: Two Metabolically-related Aminophospholipids, Journal of Lipid Research, Vol.49, 1377-1387, 2008.

[40] F. Gibellini, T. Smith. The Kennedy pathway-de novo synthesis of phosphatidylethanolamine and phosphatidylcholine.International Union of Biochemistry and Molecular Biology, Vol.62, 414-428, 2010.

[41] J. Vance, G. Tasseva. Formation and function of phosphatidylserine and phosphatidylethanolamine in mammalian cells, Biochimica et BiophysicaActa, Vol.1831, No. 3, 543-554, 2013.

[42] K. Shigemi, K. Tanaka, K. Hayamizu, D. Denbow, M. Furuse. L-Serine Decreases Taurine Concentration in the Extracellular Fluid of Brain Slices, Neuroscience and Medicine, No.2, 268-274, 2011.

[43] R. Rosa, R. Calado, A. Andrade, L. Narciso, M. Nunes.
Changes in amino acids and lipids during embryogenesis of European lobster, Homarusgammarus(Crustacea: Decapoda), Comparative Biochemistry and Physiology, Vol.140 B, No.2, 241-249, 2005.

[44] J. Slotte. Biological functions of sphingomyelins, Progress in Lipid Research, Vol. 52, No. 4, 424-437, 2013.

[45] F. Gibellini, W. Hunter, T. Smith. The ethanolamine branch of the kennedy pathway is essential in the bloodstream form of Trypanosomabrucei, Molecular Microbiology, Vol.73, 826-843, 2009.

[46] Z. Pavlovic, M. Bakovic. Regulation of Phosphatidylethanolamine Homeostasis - The Critical Role of CTP:PhosphoethanolamineCytidylyltransferase (Pcyt2), International Journal of Molecular Sciences, Vol.14, 2529-2550, 2013.

[47] C. Vines. Phospholipase C. Advances in Experimental Medicine and Biology, Vol.740, 235-54, 2012.

[48] P. Suh, J. Park, L. Manzoli, L. Cocco, J. Peak, M. Katan, K. Fukami, T. Kataoka, S. Yun, S. Ryu. Multiple roles of phosphoinositide-specific phospholipase C isozymes, Biochemistry and Molecular Biology Reports, Vol.41, 415-434, 2008.

[49] É. Dyatlovitskaya, V. Volkova, M. Ispolatovskaya, L. Bergel'son. Decomposition of phosphatidylethanolamine with phospholipase $\mathrm{C}$ from Clostridium perfringens, Bulletin of the Academy of Sciences of the USSR, Division of chemical science, Vol.16, No.2, 402-404, 1967.

[50] M. Chang, B. Roots. The effect of temperature-and oxygen-acclimation on phospholipids of goldfish (Carassiusauratus L.) brain mitochondria, Neurochemical Research, Vol.10, No.9, 1231-1246, 1985.

[51] M. Chang, B. Roots. Influence of environmental temperature on the phospholipid composition of outer and inner mitochondrial membranes from goldfish (Carassiusauratus L.) brain, Journal of Thermal Biology, Vol.13, 61-66, 1988.

[52] A. Calabretti, F. Cateni, G. Procida, L. Favretto. Influence of environmental temperature on composition of lipids in edible flesh of rainbow trout (Oncorhynchusmykiss), Journal of the Science of Food and Agriculture, Vol. 83, 1493-1498, 2003.

[53] R. Sundler, B. Ákesson. Regulation of phospholipid biosynthesis in isolated rat hepatocytes.Effect of different substrates, The Journal of Biological Chemistry, Vol.250, 3359-3367, 1975.

[54] M. Houweling, L. Tijburg, W. Vaartjes, L. Van Golde. Phosphatidylethanolamine metabolism in rat liver after partial hepatectomy, Biochemical Journal, Vol.283, 55-61, 1992.

[55] H. Tallan, S. Moore, W. Stein. Studies on the free amino acids and related compounds in the tissues of the cat, The Journal of Biological Chemistry,Vol.211, 927-939, 1954.

[56] J. Bostwick, R. Abbe, S. Appel. Phosphoethanolamine enhances high-affinity choline uptake and acetylcholine synthesis in dissociated cell cultures of the rat septal nucleus, Journal of Neurochemistry, Vol.59, No.1, 236-244, 1992.

[57] A. Ferreira, R. Meneguelo, S. Neto, G. Chierice, D. Maria. Synthetic Phosphoethanolamine Induces Apoptosis Through Caspase-3 Pathway by Decreasing Expression of Bax/Bad 
Protein and Changes Cell Cycle in Melanoma, Journal of Cancer Science \& Therapy, Vol.3, 53-59, 2011.

[58] M. Zeise, A. Lehmann. Phosphoethanolamine transiently enhances excitability of rat hippocampal neurons in vitro, Journal of Comparative Physiology A: Neuroethology, Sensory, Neural, and Behavioral Physiology, Vol.161, Vol.3, 461-467, 1987.

[59] D. Ellison, M. Beal, J. Martin. Phosphoethanolamine and ethanolamine are decreased in Alzheimer's disease and Huntington's disease, Brain Research, Vol.417, No.2, 389-392, 1987.
[60] W. Klunk, R. McClure, J. Pettegrew. L-phosphoserine, a metabolite elevated in Alzheimer's disease, interacts with specific L-glutamate receptor subtypes, Journal of Neurochemistry, Vol.56, No.6, 1997-2003, 1991.

[61] W. Klunk, M. Debnath, R. McClure, J. Pettegrew. Inactivity of phosphoethanolamine, an endogenous GABA analog decreased in Alzheimer's disease, at GABA binding sites, Life sciences, Vol.56, 2377-2383, 1995. 